Kiryoku, Volume 3 No 42019

e-ISSN: 2581-0960 p-ISSN: 2599-0497

Tersedia online di http://ejournal.undip.ac.id/index.php/kiryoku

\title{
Refleksi Ajaran Shinto Dalam Omamori
}

\author{
Yuliani Rahmah \\ Universitas Diponegoro \\ Email :yuliani.rahmah@live.undip.ac.id
}

\begin{abstract}
Abstrak
Ajaran Shinto yang diturunkan dari generasi ke generasi telah memberikan pengaruh kuat pada kehidupan masyarakat Jepang, dari mulai kegiatan festival sampai pada benda-benda yang berada dalam lingkungan sekitarnya.Omamori merupakan salah satu wujud budaya yang dianggap sebagai bagian dari harmonisasi dari ajaran Shinto dan Budha yang menjadi kepercayaan utama masyarakat Jepang. Sebagai salah satu benda keramat yang sampai saat ini masih dipercaya oleh masyarakat Jepang, keberadaan omamori begitu populer bahkan dalam masyarakat modern. Melalui kajian kepustakaan, artikel ini bertujuan untuk memaparkan bagian apa saja dari omamori yang merupakan refleksi dari ajaran Shinto. Hasil yang didapatkan menunjukkan bahwa refleksi tersebut antara lain terlihat pada kepercayaan pengguna omamori akan keberadaan dan kekuatan kamisama (dewa) dan roh jahat, juga terlihat material dari omamori itu sendiri.
\end{abstract}

Kata Kunci : Ajaran Shinto; Omamori ; Kamisama

\begin{abstract}
(Title: Shintoism Reflection InOmamori) Shinto handed down from generation to the next generation. Shintoism have had a strong influence on the lives of Japanese people, from festival activities to objects in their surroundings. Omamori is known as one form of that influence and became a culture part of the harmonization of the Shintoism and Buddhism. As one of the sacred objects which are still trusted by Japanese people, the existence of omamori is so popular even in modern society. Through a literature review, this article aims to describe what parts of the omamori are a reflection of Shintoism. The results obtained show that the reflection can be seen among others in the omamori user's belief in the existence of kamisama (Gods), and evil spirits, also can be seen from the material of the omamori itself.
\end{abstract}

Keywords:Shintoism Philosophy;Omamori; Kamisama

\section{PENDAHULUAN}

Agama Shinto dianggap sebagai agama asli masyarakat Jepang yang telah diyakini sejak ratusan tahun yang lalu. Shinto berasal dari dua karakter kanji, yaitu kanji 神 (bermakna “dewa”) dan kanji 道 (bermakna "jalan") sehingga Shinto dimaknai sebagai jalan dewa. Shinto menjadi agama resmi pada masa restorasi Meiji, dan dalam perkembangannya ajaran Shinto terbagi menjadi Shinto sekte dan Shinto agama. Bahkan lebih jauh dengan kemunculan gerakan keagamaan di Jepang, lahir pula kelompok-kelompok yang membedakan dirinya menjadi setengah Shinto dan sebagainya.

Meskipun sebagian besar masyarakat Jepang mengakui bahwa mereka bukanlah penganut Shinto, namun hingga sekarang konsep ajaran Shinto masih melekat kuat dan menjadi bagian penting dalam kehidupan sehari-hari masyarakat Jepang. Selain pada ritual keagamaan penerapan konsep Shinto 
tersebut terlihat pula pada festival-festival dan benda-benda sakral yang digunakan oleh masyarakatnya. Dalam sebuah artikel yang dimuat di https://jpninfo.com/id/667 dijelaskan bahwa setidaknya terdapat 10 buah benda sakral yang dipercaya oleh masyarakat Jepang sebagai jimat keberuntungan (engimono). Kesepuluh engimono tersebut adalah ikan koi, kaeru (katak), fukurou (burung hantu), maneki neko (kucing pemanggil), boneka Daruma, Tsuru (burung bangau), Daikokuten (dewa kemakmuran), Hotei (Budha tertawa), Omamori (jimat keberuntungan) dan Matsu (pohon pinus). Bila dilihat dari jenis benda yang dianggap keramat, terlihat adanya pengaruh Shinto dan budha dalam bentuk benda-benda tersebut,dan salah satunya adalah omamori yang dianggap sebagai jimat pembawa keberuntungan bagi pemiliknya.

Tulisan kali ini merupakan lanjutan dari tulisan sebelumnya yang telah membahas tentang omamori. Tulisan terdahulu hanya membahas omamori dilihat dari bentuk dan fungsinya saja, pada pemaparan kali ini penulis akan mencoba memaparkan mengenai refleksi ajaran Shinto yang melekat pada sebuah omamori.

Penelitian baik tentang omamori maupun agama Shinto sendiri sudah banyak dilakukan. Beberapa diantaranya adalah sebagai berikut.Penelitian tentang omamori pernah dilakukan oleh Dania Sakti (2008), mahasiswa Universitas Gadjah Mada. Dalam skripsinya yang berjudul Persepsi Kaum Muda Jepang Terhadap Omamori, Dania memperoleh kesimpulan bahwa di kalangan kaum muda Jepang keberadaan omamori masih diakui, namun sebagian besar dari mereka tidak mempercayai kekuatan gaib yang terdapat di dalamnya. Penelitian lain dilakukan oleh Wulan Dwi Savitri (2018), mahasiswa Universitas Sumatra Utara dalam skripsinya yang berjudul Fungsi dan Makna Omamori bagi Masyarakat Jepang.
Dalam skripsinya penulis menjelaskan bahwa berdasarkan fungsi dan maknanya yang beragam sebuah omamori dapat menjadi motivator bagi masyarakat Jepang untuk bekerja lebih giat agar berhasil dalam kehidupannya.

Penelitian tentang Shinto pun pernah dilakukan baik dalam bentuk artikel pada jurnal maupun skripsi. Penelitian tersebut antara lain artikel yang ditulis oleh Budi Mulyadi (2017) berjudul Konsep Agama dalam Kehidupan Masyarakat Jepang. Dalam artikel tersebut dijelaskan berbagai agama yang berkembang di masyarakat Jepang dan salah satunya adalah penjelasan mengenai keberadaan agama Shinto . Penelitian lain dilakukan oleh Ratna Handayani dkk (2009) mahasiswa Universitas Bina Nusantara. Dalam tulisannya yang berjudul Eksistensi Shinto dalam Shogatsu, melalui hasil angketnya para penulis menjelaskan mengenai keterkaitan ajaran Shinto pada perayaan shogatsu yang secara rutin dilakukan oleh masyarakat Jepang.

Dari beberapa penelitian tersebut dapat dilihat bahwa pada umumnya hasil penelitian menjelaskan konsep agama Shinto dan omamori dalam kajian yang terpisah, namun pada pemaparan kali ini penulis akan mencoba menjelaskan bagaimana konsep ajaran Shinto diwujudkan dalam bentuk benda sakral yang hingga sekarang keberadaannya masih dibutuhkan oleh masyarakat Jepang. Dengan pemikiran tersebut maka tujuan dari tulisan kali ini adalah untuk mendeskripsikan bagian apa saja dari konsep ajaran Shinto yang terdapat pada sebuah omamori, sehingga diharapkan tulisan kali ini akan lebih mengungkap fakta menarik dari keberadaan omamori yang merupakan warisan Shinto namun dipercaya oleh masyarakat Jepang bahkan oleh mereka yang mengaku bukan penganut ajaran Shinto . 
Kiryoku, Volume 3 No 42019

e-ISSN: 2581-0960 p-ISSN: 2599-0497

Tersedia online di http://ejournal.undip.ac.id/index.php/kiryoku

\section{METODE}

Metode yang digunakan dalam pembahasan ini adalah studi pustaka. Studi pustaka digunakan untuk menganalisa masalah yang dikaji dengan menggunakan berbagai macam literatur sebagai sumber data primer. Adapun langkah-langkahg penelitian yang dilakukan adalah observasi terhadap objek kajian agar mendapatkan gambaran mengenai kepercayaan yang dianut oleh masyarakat Jepang, salah satunya adalah kepercayaan terhadap ajaran Shinto dan benda-benda yang mereka sakralkan. Langkah selanjutnya adalah analisa data yang dilakukan atas bahan informasi/ data-data yang sudah diperoleh dan diperkuat bahan/informasi dari buku ,jurnal dan artikel website yang sudah ada.

Data yang diperoleh dari hasil analisa kemudian dipaparkan dengan menggunakan metode deskriptif.

\section{HASIL DAN PEMBAHASAN}

\section{A. Konsep Ajaran Shinto}

Shinto merupakan agama asli masyarakat Jepang. Tidak diketahui secara pasti siapa yang pertama kali mengajarkan agama Shinto, bahkan awalnya agama ini tidak mempunyai nama, dogma bahkan kitab suci.Mengenai kapan Shinto sendiri dikenal di Jepang, dalam The Kondansha Bilingual Encyclopedia of Japan dijelaskan hal berikut :

神道という言葉は「日本書紀」（72 0 年）において初めて用いられ、宗教 儀式、神、神社などを意味した。特定 の宗教の教義を表す言葉として使われ るようになったのは 12 世紀後半にな ってからである。（Kodansha,1998； 499)

Dari penjelasan di atas dapat diketahui bahwa kata Shinto pertama kali digunakan pada sebuah buku berjudul Nihon shoki (sekitar tahun 720) dan artinya mengacu pada ajaran agama, dewa, dan juga kuil sebagai tempat peribadatannya.

Bila dilihat dari sudut literasinya, Nihonshoki sendiri bersama Kojiki merupakan sebuah karya sastra kuno yang dikenal dengan sebutan mitologi Kiki. Dalam mitologi Kiki tersebut cerita yang disampaikan ajaran-ajaran Shinto yang terkait dengan asal-usul alam semesta, terjadinya daratan, lahirnya dewa dewi dan keluarga kaisar. (Rahmah,2014; 3-4)

Memperhatikan keberadaannya yang sudah sangat lama, maka Shinto dianggap sebagai satu kepercayaan kuno yang menyebar secara turun menurun pada masyarakat Jepang. Oleh karena itu tidaklah mengherankan bila ajaran tersebut sudah mengakar dalam sendisendi kehidupan sehari-hari masyarakat,tidak hanya dalam pelaksanaan ritual dan festival tahunannya tetapi juga terlihat pada benda-benda yang digunakan dalam kehidupan masyarakatnya. Shinto pun diyakini sebagai sebuah kepercayaan asli dari Jepang yang lahir sejak zaman prasejarah dan juga merupakan tradisi indigenous yang diterapkan turun temurun.

Dalam ajarannya kesucian sangat ditekankan dalam segala aspek kehidupan. Shinto meyakinkan pengikutnya agar selalu menjaga kebersihan dan kesucian baik itu kesucian secara fisik ataupun batin (Pratiwi, 2017:174)

Shinto sebagai sebuah kepercayaan rakyat mempercayai bahwa seluruh alam semesta ini merupakan tempat berdiamnya "kami gami" atau para dewa. Kami gami tersebut tidak terbatas hanya berdiam di sebuah tempat tertentu saja, namun bisa juga berdiam pada sebuah benda. Itulah sebabnya para penganut Shinto mempunyai kewajiban untuk menjaga dan menghormati alam semesta. Bentuk 
kewajiban tersebut dikenal dengan sebutan Shizenkan (自然感). Masyarakat Jepang pun mempercayai bahwa Jinja adalah tempat tinggal kami gami (para dewa).

Tiap jinja didiami oleh tiap kami tertentu yang disembah oleh orang Jepang sesuai dengan fungsi dan kebutuhan yang sifatnya duniawi. Selain itu juga terdapat anggapan bahwa selain jinja juga benda-benda yang berasal dari alam semesta dianggap sebagai tempat atau simbol bersemayamnya para dewa (Herlina,2011;117)

Hampir semua masyarakat Jepang mempraktikkan ajaran Shinto meskipun mereka mengaku bukan sebagai penganut agama tersebut. Dalam setiap festivalfestival tahunan yang diadakan semua anggota masyarakat datang ke kuil-kuil untuk merayakannya tanpa harus terikat pada organisasi resmi agama Shinto .

Dalam ajaran Shinto kepercayaan terhadap harmonisasi kekuatan kami menjadi hal yang sangat penting.Keberadaan kami adalah di setiap obyek alam, seperti gunung, hutan, air terjun, angin, dan sebagainya. Kami pun bahkan ada dalam sosok binatang seperti rubah, anjing dan kucing. Masyarakat Jepang percaya bahwa Kami tertinggi berada di Gunung Fuji, Jepang yang merupakan pusat kosmos.

Alam sendiri merupakan bagian yang terdiri dari energi positif dan negatif yang dapat menimbulkan sifat baikdan buruk (jahat). Dengan keberadaan kami dalam objek alam, maka dipercaya akan dapat membimbing pada jalan lurus sehingga setiap orang dapat hidup sesuai jalan kebenaran.Seseorang yang menjalani kehidupan sesuai dengan petunjuk kami maka dipercaya akan mendapat perlindungan dari kami, karena dalam pandangan agama Shinto setiap manusia yang diberikan hidup oleh kami dan kehidupannya adalah suci.Setelah penyebaran ajaran Shinto kemudian menyebar ajaran Budha di Jepang.
Budha yang datang dan berkembang di Jepang pada sekitar abad ke 6 harus melewati proses penyesuaian yang panjang sebelum akhirnya dapat menjadi bagian dari masyarakat penganut Shinto kala itu. Pertumbuhan kedua agama ini menghasilkan suatu interaksi yang harmonis antara dewa-dewa kepercayaan Shinto dan dewa-dewa kepercayaan Budha (Rahmah,2019;93)

Meskipun kemudian agama Budha juga menjadi agama yang cukup kuat keberadaannya dalam kehidupan masyarakat Jepang, namun kemampuan penyebaran ajaran Budha dalam beradaptasidengan kehidupan masyarakat Jepang telah menimbulkan harmonisasi antara keduanya. Banyak dari orang Jepang yang berpandangan bahwa bila kedua agama tersebut dibandingkan maka agama Budha diakui telah memperdalam dan memperhalus ajaran Shinto. Ini pula yang menjadi sebab mengapa kedua ajaran ini begitu menyatu dalam kehidupan masyarakat Jepang.

\section{B. Pengaruh Ajaran Shinto dalam Omamori}

Omamori merupakan jimat pelindung yang diperoleh orang Jepang pada saat mereka mengunjungi jinja atau otera untuk melakukan ritual doa.

Omamori tersebut pada umumnya berbentuk sebuah kantung terbuat dari kain berdekorasi dimana di dalam kain tersebut terdapat lipatan kertas atau potongan kayu yang bertuliskan nama dewa. Lipatan kertas tersebut sudah didoakan agar memberikan perlindungan dan keberuntungan pada si pemiliknya. Masyarakat Jepang percaya bahwa omamori adalah sebuah benda keramat yang menyimpan kekuatan dewa atau Budha (Rahmah,2019;95)

Dalam kaitannya dengan ajaran Shinto , maka Shinto yang merupakan 
Kiryoku, Volume 3 No 42019

e-ISSN: 2581-0960 p-ISSN: 2599-0497

Tersedia online di http://ejournal.undip.ac.id/index.php/kiryoku

kepercayaan asli masyarakat Jepang memberikan pengaruh sehingga mereka percaya akan kekuatan sebuah omamori.Seperti juga kepercayaan pada Shinto, penggunaan omamori dalam kehidupan masyarakat Jepang pun telah dilakukan secara turun temurun dari generasi ke generasi. Dengan berkembangnya ajaran Shinto dan Buddha yang kemudian mengakar kuat pada kehidupan masyarakat Jepang, terlihat bahwa omamori merupakan salah satu warisan nenek moyang yang mendapat pengaruh cukup kuat dari kedua agama tersebut. Namun, dalam pemaparan kali ini penulis hanya akan membahas salah satunya yaitu bentuk pengaruh ajaran Shinto pada omamori. Berikut adalah pengaruh ajaran Shinto yang dapat dilihat pada keberadaan omamori.

1. Hal pertama yang bisa kita lihat dari pengaruh Shinto dalam sebuah omamori adalah kepercayaan itu sendiri. Shinto adalah agama kuno yang mencampurkan kepercayaan animisme dan dinamisme. Keyakinan seperti ini merupakan kepercayaan primitf yang menyakini kekuatan alam, benda atau roh.Kepercayaan tua seperti ini biasanya penuh dengan berbagai ritual dan perayaan yang biasanya berhubungan dengan musim panen, roh, spirit dan lain-lain. (Ardika,2010). Omamori yang merupakan jimat pelindung dipercaya berisikan spirit para dewa yang bersemayam di dalamnya, sehingga ada kepercayaan bahwa omamori tidak boleh dibuka karena diyakini kekuatan spiritnya akan menghilang.

2. Pengaruh selanjutnya bisa dilhat pada penggunaan material dari omamori itu sendiri. Ajaran Shinto menjungjung tinggi keberadaan dan harmonisasi dengan alam. Wujud omamori pada umumnya berbentuk sebuah kantung terbuat dari kain berdekorasi dimana di dalam kain tersebut terdapat lipatan kertas atau potongan kayu yang bertuliskan nama dewa. Penggunaan potongan kayu dan kertas merupakan refleksi penghormatan pada alam dan keberadaan kami. Keyakinan penganut ajaran Shinto bahwa kami gami bersemayam dimanapun dan dalam wujud apapun, membuat omamori dipercaya sebagai wujud kekuatan kami yang bersemayam dalam sebuah benda.

3. Kepercayaan bahwa setiap dewa mempunyai kekuatan yang berbedabeda membuat masyarakat Jepang percaya bahwa jenis omamori dapat digunakan sesuai dengan kebutuhan dan keinginan tertentu. Itulah juga yang menjadi sebab mengapa di Jepang omamori mempunyai banyak bentuk dan jenis. Setiap jenis dipercaya sebagai tempat bersemayam dewa tertentu yang akan membantu mewujudkan keinginan mereka. Selain itu dengan adanya kepercayaan bahwa kami bisa terdapat dalam sosok binatang, memunculkan pula bentuk omamori seperti rubah, kucing dan anjing.

4. Kepercayaan bahwa setiap manusia yang diberikan hidup oleh kami dan kehidupannya adalah suci. Hal ini menjadi dasar adanya kepercayaan bahwa manusia itu makhluk baik dimana kejahatan yang dilakukan oleh manusia itu disebabkan oleh adanya pengaruh roh jahat. Dengan kepercayaan tersebut maka agar terhindar dari gangguan roh jahat,manusia membutuhkan omamori sebagai media kekuatan para dewa untuk mencegah masuknya roh jahat di kehidupan. Dengan memiliki omamori maka kekuatan kami yang terdapat di dalamnya akan dapat membimbing pada jalan lurus sehingga mereka yang menjalani kehidupan sesuai dengan petunjuk kami tersebut mendapat perlindungan.

5. Kepercayaan Shinto terhadap adanya kekuatan roh jahat dan hal buruk yang akan mempengaruhi kesucian hidup manusia, mendorong penganutnya 
melakukan ritual doa (yang merupakan komponen utama dalam ajaran Shinto) pada seluruh kegiatan di sepanjang hidupnya. Ritual doa sebagai pengharapan mereka pada perlindungan dan penjagaan kamigamitersebut kemudian diwujudkan dalam bentuk omamori yang digunakan sebagai jimat perlindungan untuk menghindari nasib buruk dalam setiap siklus kehidupan seseorang. Siklus kehidupan tersebut dalam jenis omamori yang mempunyai fungsi berbeda. Doa dan permohonan perlindungan dalam siklus pertama kehidupan seseorang dimulai sejak manusia itu akan dilahirkan. Pada fase ini masyarakat Jepang akan berdoa dan melakukan permohonankepada kami yang menjaga kesehatan dan kelancaran kelahiran seorang bayi melalui anzan-mamori (安産). Kemudian ketika seseorang mulai memasuki dunia pendidikan mereka menggantungkan harapan dan doa mereka terhadap kekuatan kami yang terdapat dalam Gakugyoujoju-mamori (学業成就) dan ketika mereka memasuki dunia usaha mereka menggunakan Shoubai Hanjo-mamori (商売繫盛) untuk mendapatkan bantuan kami dalam memperlancar bisnis yang mereka jalankan. Ketika siklus kehidupan seseorang tiba pada fase mencari pasangan hidup, maka terdapat En Musubi-mamori (縁結び) yang diyakini akan membantu pemiliknya menemukan pasangan dan pernikahan melalui petunjuk dan kekuatan kami yang berada di dalam omamori tersebut. Selain doa dan perlindungan untuk setiap fase kehidupan, terdapat pula omamori yang dipercaya akan melindungi mereka dari pengaruh negatif seperti Yaku Yoke- omamori (厄 除) yang dipercaya dapat melindungi pemiliknya dari gangguan setan atau hal-hal yang bersifat gaib atau Kotsuu Anzen-mamori (交通安全) yang dipercaya dapat menjaga keselamatan pemiliknya pada saat melakukan perjalanan.

\section{SIMPULAN}

Keberadaaan omamori yang diyakini masyarakat Jepang sebagai jimat pelindung dalam menjalani kehidupan mereka kental dengan pengaruh agama Shinto yang juga telah menjadi kepercayaan kuno masyarakat Jepang. Meskipun sebagian besar masyarakat Jepang mengakui mereka bukan penganut Shinto saat mendatangi kuil untuk memperoleh sebuah omamori, namun pengaruh ajaran Shinto yang terefleksi pada wujud omamori itu sendiri merupakan sebuah bukti bahwa ajaran Shinto melekat kuat dalam karakter masyarakat Jepang sebagai bagian dari warisan yang tidak terpisahkan darikehidupan keseharian mereka.

Modernisasi, kemajuan teknologi bahkanpengakuan masyarakat Jepang yang pada umumnya tidak memeluk suatu agama atau kepercayaan tertentu nampaknya tidak mengikis kepercayaan mereka pada kekuatan spiritual yang terkandung dalam omamori sebagai bagian dari refleksi ajaran Shinto . Kepercayaan dan filosofi yang diajarkan dalam Shinto sebagian besar dapat dilihat dari jenis dan penggunaan omamori itu sendiri

\section{REFERENSI}

Anonim. (1998). The Kondansha Bilingual Encyclopedia of Japan. Tokyo : Kondansha International Ltd.

Ardika, Nyoman, (2010). Mengenal Agama Shinto Retrieved from http://www.eonet.ne.jp/ limadaki/ budaya/jepang/artikel/utama/agam a shinto.html 
Kiryoku, Volume 3 No 42019

e-ISSN: 2581-0960 p-ISSN: 2599-0497

Tersedia online di http://ejournal.undip.ac.id/index.php/kiryoku

Handayani, Ratna. (2009). Eksistensi

Shinto dalam Shougatsu.Jurnal

Lingua Cultura 3 (1)

Herlina,Sandra. (2011). Suatu Telaah

Budaya : Agama dalam Kehidupan

Orang Jepang. Jurnal Al-Azhar

Indonesia Seri Humaniora. 1 (2)

Mulyadi, Budi. (2017). Konsep Agama dalam Kehidupan Masyarakat Jepang. Jurnal Izumi 1 (1)

Pratiwi, Citra Ayu. (2017). Harai : Telaah KonsepReligi Koentjaraningrat. Jurnal Japanology 5(2)

Rahmah, Yuliani. (2014). Sejarah Kesusastraan Jepang. Buku Ajar Program Studi Bahasa dan Kebudayaan Jepang Fakultas Ilmu Budaya Universitas Diponegoro.Tidak dipublikasikan

2019. Omamori dalam Kepercayaan Masyarakat Jepang. Jurnal Kiryoku 3 (2)

Savitri, Wulan Dwi (2018). Fungsi dan Makna Omamori bagi Masyarakat Jepang.

Retrievedfrom http://repositori.usu.ac.id/h andle/123456789/2975

Sumber intermet :

https://jpninfo.com/id/667

Diunduh tanggal 10 Juni 2019 